Reply

\title{
Reply to Comment on Tsai, Y.-C., et al. Association of Stress-Induced Hyperglycemia and Diabetic Hyperglycemia with Mortality in Patients with Traumatic Brain Injury: Analysis of a Propensity Score-Matched Population. Int. J. Environ. Res. Public Health 2020, 17, 4266
}

\author{
Yu-Chin Tsai ${ }^{1}$, Shao-Chun $\mathrm{Wu}^{2}{ }^{\circledR}$, Ting-Min Hsieh ${ }^{3}$, Hang-Tsung Liu ${ }^{3}$, Chun-Ying Huang ${ }^{3}{ }^{\circledR}$, Sheng-En Chou ${ }^{3}$, \\ Wei-Ti Su ${ }^{3}$, Shiun-Yuan $\mathrm{Hsu}^{3}$ and Ching-Hua Hsieh ${ }^{3, *(D)}$ \\ 1 Department of Neurosurgery, Kaohsiung Chang Gung Memorial Hospital and Chang Gung University \\ College of Medicine, Kaohsiung 83301, Taiwan; vagility@gmail.com \\ 2 Department of Anesthesiology, Kaohsiung Chang Gung Memorial Hospital and Chang Gung University \\ College of Medicine, Kaohsiung 83301, Taiwan; shaochunwu@gmail.com \\ 3 Department of Trauma Surgery, Kaohsiung Chang Gung Memorial Hospital and Chang Gung University \\ College of Medicine, Kaohsiung 83301, Taiwan; hs168hs168@gmail.com (T.-M.H.); \\ ht11688@yahoo.com.tw (H.-T.L.); junyinhaung@yahoo.com.tw (C.-Y.H.); athenechou@gmail.com (S.-E.C.); \\ s101132@adm.cgmh.org.tw (W.-T.S.); ah.lucy@hotmail.com (S.-Y.H.) \\ check for \\ updates \\ * Correspondence: m93chinghua@gmail.com
}

Citation: Tsai, Y.-C.; Wu, S.-C.; Hsieh T.-M.; Liu, H.-T.; Huang, C.-Y.; Chou, S.-E.; Su, W.-T.; Hsu, S.-Y.; Hsieh, C.-H. Reply to Comment on Tsai, Y.-C., et al. Association of Stress-Induced Hyperglycemia and Diabetic Hyperglycemia with Mortality in Patients with Traumatic Brain Injury: Analysis of a Propensity Score-Matched Population. Int. J. Environ. Res. Public Health 2020, 17, 4266. Int. J. Environ. Res. Public Health 2021, 18, 2531. https://doi.org/ 10.3390/ijerph18052531

Received: 10 February 2021 Accepted: 10 February 2021 Published: 4 March 2021

Publisher's Note: MDPI stays neutral with regard to jurisdictional claims in published maps and institutional affiliations.

Copyright: $\odot 2021$ by the authors. Licensee MDPI, Basel, Switzerland. This article is an open access article distributed under the terms and conditions of the Creative Commons Attribution (CC BY) license (https:// creativecommons.org/licenses/by/ $4.0 /)$.
Thank you for Eduardo Mekitarian Filho's appreciation of our work on the study of stress-induced hyperglycemia (SIH) and diabetic hyperglycemia (DH) in patients with traumatic brain injuries. According to our previous studies on $\mathrm{SIH}$ and $\mathrm{DH}$ in patients with various illnesses or other conditions [1-8], the mortality rate is always worse for patients with SIH than for patients with nondiabetic normoglycemia; however, such poor outcomes are not always observed in those with DH. Differentiating between the etiologies of a patient's hyperglycemic status is important not only because they can affect patient outcome but also because the goals for glucose control differ between SIH and $\mathrm{DH}$. Aggressive glucose control (i.e., maintaining glucose levels within the normal range) may be limited for those with $\mathrm{DH}$ but not for those with $\mathrm{SIH}$; because although some studies reported conflicting results, $\mathrm{SIH}$ is believed to be a physiological response that parallels the elevation of catecholamines in the body in its attempt to cope with major stress. Moreover, many questions remain unanswered in this field. For example, why do some patients develop SIH while others do not? What is the magnitude of stress required for the development of SIH? What are the risk factors for SIH? Do genetic or epigenetic factors play a role in the occurrence of SIH? What is the goal of glucose control in patients with SIH? Do any treatments specifically benefit patients with SIH? What is the role of steroids in the management of SIH? As diabetic patients may also face major stress, what is the effect of SIH in those with diabetes [4]? There are still many unanswered questions and unexplored areas with regard to $\mathrm{SIH}$; thus, further research is required to solve this problem.

Author Contributions: Conceptualization, C.-H.H.; methodology, S.-Y.H.; validation, C.-Y.H., S.-E.C. and W.-T.S.; investigation, H.-T.L.; data curation, T.-M.H.; writing-original draft prepara-tion, S.C.W.; writing - review and editing, Y.-C.T.; supervision, C.-H.H. All authors have read and agreed to the published version of the manuscript.

Funding: This research received no external funding.

Institutional Review Board Statement: Not applicable.

Informed Consent Statement: Not applicable.

Conflicts of Interest: The authors declare no conflict of interest. 


\section{References}

1. Chang, M.W.; Huang, C.Y.; Liu, H.T.; Chen, Y.C.; Hsieh, C.H. Stress-Induced and Diabetic Hyperglycemia Associated with Higher Mortality among Intensive Care Unit Trauma Patients: Cross-Sectional Analysis of the Propensity Score-Matched Population. Int. J. Environ. Res. Public Health 2018, 15, 922. [CrossRef] [PubMed]

2. Rau, C.S.; Wu, S.C.; Chen, Y.C.; Chien, P.C.; Hsieh, H.Y.; Kuo, P.J.; Hsieh, C.H. Higher Mortality in Trauma Patients Is Associated with Stress-Induced Hyperglycemia, but Not Diabetic Hyperglycemia: A Cross-Sectional Analysis Based on a Propensity-Score Matching Approach. Int. J. Environ. Res. Public Health 2017, 14, 1161. [CrossRef] [PubMed]

3. Rau, C.S.; Wu, S.C.; Chen, Y.C.; Chien, P.C.; Hsieh, H.Y.; Kuo, P.J.; Hsieh, C.H. Stress-Induced Hyperglycemia, but Not Diabetic Hyperglycemia, Is Associated with Higher Mortality in Patients with Isolated Moderate and Severe Traumatic Brain Injury: Analysis of a Propensity Score-Matched Population. Int. J. Environ. Res. Public Health 2017, 14, 1340. [CrossRef] [PubMed]

4. Rau, C.S.; Wu, S.C.; Chen, Y.C.; Chien, P.C.; Hsieh, H.Y.; Kuo, P.J.; Hsieh, C.H. Stress-Induced Hyperglycemia in Diabetes: A Cross-Sectional Analysis to Explore the Definition Based on the Trauma Registry Data. Int. J. Environ. Res. Public Health 2017, 14, 1527. [CrossRef] [PubMed]

5. Rau, C.S.; Wu, S.C.; Chen, Y.C.; Chien, P.C.; Hsieh, H.Y.; Kuo, P.J.; Hsieh, C.H. Mortality Rate Associated with Admission Hyperglycemia in Traumatic Femoral Fracture Patients Is Greater Than Non-Diabetic Normoglycemic Patients but Not Diabetic Normoglycemic Patients. Int. J. Environ. Res. Public Health 2017, 15, 28. [CrossRef] [PubMed]

6. Su, W.T.; Wu, S.C.; Chou, S.E.; Huang, C.Y.; Hsu, S.Y.; Liu, H.T.; Hsieh, C.H. Higher Mortality Rate in Moderate-to-Severe Thoracoabdominal Injury Patients with Admission Hyperglycemia Than Nondiabetic Normoglycemic Patients. Int. J. Environ. Res. Public Health 2019, 16, 3562. [CrossRef]

7. Tsai, Y.C.; Wu, S.C.; Hsieh, T.M.; Liu, H.T.; Huang, C.Y.; Chou, S.E.; Su, W.T.; Hsu, S.Y.; Hsieh, C.H. Association of Stress-Induced Hyperglycemia and Diabetic Hyperglycemia with Mortality in Patients with Traumatic Brain Injury: Analysis of a Propensity Score-Matched Population. Int. J. Environ. Res. Public Health 2020, 17, 4266. [CrossRef]

8. Tsai, Y.W.; Wu, S.C.; Huang, C.Y.; Hsu, S.Y.; Liu, H.T.; Hsieh, C.H. Impact of Stress-Induced Hyperglycemia on the Outcome of Children with Trauma: A Cross-Sectional Analysis Based on Propensity Score-Matched Population. Sci. Rep. 2019, 9, 16311. [CrossRef] [PubMed] 